\title{
False Negatives for Remote Life Detection on Ocean-Bearing Planets: Lessons from the Early Earth
}

\author{
Christopher T. Reinhard, ${ }^{1,2}$ Stephanie L. Olson, ${ }^{1,3}$ Edward W. Schwieterman, ${ }^{1,3,4,5}$ and Timothy W. Lyons $s^{1,3}$
}

\begin{abstract}
Ocean-atmosphere chemistry on Earth has undergone dramatic evolutionary changes throughout its long history, with potentially significant ramifications for the emergence and long-term stability of atmospheric biosignatures. Though a great deal of work has centered on refining our understanding of false positives for remote life detection, much less attention has been paid to the possibility of false negatives, that is, cryptic biospheres that are widespread and active on a planet's surface but are ultimately undetectable or difficult to detect in the composition of a planet's atmosphere. Here, we summarize recent developments from geochemical proxy records and Earth system models that provide insight into the long-term evolution of the most readily detectable potential biosignature gases on Earth-oxygen $\left(\mathrm{O}_{2}\right)$, ozone $\left(\mathrm{O}_{3}\right)$, and methane $\left(\mathrm{CH}_{4}\right)$. We suggest that the canonical $\mathrm{O}_{2}-\mathrm{CH}_{4}$ disequilibrium biosignature would perhaps have been challenging to detect remotely during Earth's 4.5-billion-year history and that in general atmospheric $\mathrm{O}_{2} / \mathrm{O}_{3}$ levels have been a poor proxy for the presence of Earth's biosphere for all but the last $\sim 500$ million years. We further suggest that detecting atmospheric $\mathrm{CH}_{4}$ would have been problematic for most of the last $\sim 2.5$ billion years of Earth's history. More broadly, we stress that internal oceanic recycling of biosignature gases will often render surface biospheres on ocean-bearing silicate worlds cryptic, with the implication that the planets most conducive to the development and maintenance of a pervasive biosphere will often be challenging to characterize via conventional atmospheric biosignatures. Key Words: BiosignaturesOxygen-Methane-Ozone-Exoplanets-Planetary habitability. Astrobiology 17, 287-297.
\end{abstract}

\section{Introduction}

$\mathbf{I}^{\mathrm{N}}$ N THE TWO DECADES since the first radial velocity surveys detected distant planets orbiting Sun-like stars (Mayor and Queloz, 1995), the burgeoning field of exoplanet research has yielded an astonishing number and diversity of extrasolar worlds. At the time of this writing, there are 2331 confirmed exoplanets, with an additional 2365 candidate planets in the Kepler field of view (Akeson et al., 2013), many of which will likely be confirmed as additional exoplanets. The size, orbital parameters, and composition of these planets are staggering in their diversity (e.g., Pierrehumbert, 2013), and the continued discovery and characterization of these worlds may ultimately have the potential to yield our first evidence for life beyond Earth.
Despite the anticipation that detection and analysis of exoplanetary atmospheres would be difficult or impossible to perform routinely, over three dozen exoplanetary atmospheres have been observed to date (Seager and Deming, 2011; Seager, 2013). The next generation of space telescopes, including the James Webb Space Telescope (JWST) and Transiting Exoplanet Survey Satellite (TESS), are expected to detect and/or characterize a number of transiting exoplanets in unprecedented detail (see, for example, Gardner et al., 2006; Deming et al., 2009; Cowan et al., 2015). Large spacebased telescope missions currently in their science definition phase would possess the capability to directly image terrestrial exoplanets at UV to near-IR wavelengths (e.g., Dalcanton et al., 2015; Mennesson et al., 2016), while future groundbased observatories will also be able to spectrally characterize

\footnotetext{
${ }^{1}$ NASA Astrobiology Institute.

${ }^{2}$ School of Earth and Atmospheric Sciences, Georgia Institute of Technology, Atlanta, Georgia.

${ }^{3}$ Department of Earth Sciences, University of California, Riverside, California.

${ }_{5}^{4}$ NASA Postdoctoral Program, Universities Space Research Association, Columbia, Maryland.

${ }^{5}$ Blue Marble Space Institute of Science, Seattle, Washington.

(c) Christopher T. Reinhard et al., 2017; Published by Mary Ann Liebert, Inc. This Open Access article is distributed under the terms of the Creative Common Attribution Noncommercial License (http://creativecommons.org/licenses/by-nc/4.0/) which permits any noncommercial use, distribution, and reproduction in any medium, provided the original author(s) and the source are credited.
} 
the atmospheres of small planets around the very nearest stars (e.g., Snellen et al., 2013, 2015). Indeed, for the foreseeable future our only accessible method for detecting life or even fully characterizing habitability beyond Earth will likely be deciphering the chemistry of exoplanetary atmospheres (Meadows and Seager, 2010; Seager, 2014).

The prospect of remotely analyzing the composition of potentially habitable exoplanetary surfaces and atmospheres provides strong impetus for the development of biosignatures that can be used to diagnose the presence and scope of a surface biosphere. The most prominent of these approaches emphasize the potential of a planet's biosphere to reshape atmospheric chemistry and in particular to drive chemical disequilibrium via large production fluxes of incompatible volatile species (Lovelock, 1965; Hitchcock and Lovelock, 1967; Sagan et al., 1993; Kaltenegger et al., 2007; Meadows and Seager, 2010; Seager et al., 2013a; Krissanson-Totton et al., 2016). The most frequently cited example of this concept is the coexistence of molecular oxygen $\left(\mathrm{O}_{2}\right)$ and methane $\left(\mathrm{CH}_{4}\right)$ in the modern Earth's atmosphere at abundances that are many orders of magnitude out of thermodynamic equilibrium (e.g., Hitchcock and Lovelock, 1967), but this concept can be functionally extended to include, for example, the coexistence of $\mathrm{N}_{2}, \mathrm{O}_{2}$, and $\mathrm{H}_{2} \mathrm{O}$ in Earth's modern oceanatmosphere system at levels strongly out of thermodynamic equilibrium with aqueous $\mathrm{H}^{+}$and $\mathrm{NO}_{3}{ }^{-}$(Krissanson-Totton et al., 2016).

Significant effort has been expended to understand abiotic mechanisms for generating the most prominent among the possible atmospheric biosignatures, particularly falsepositive signatures based on oxygen $\left(\mathrm{O}_{2}\right)$ and ozone $\left(\mathrm{O}_{3}\right)$. A number of "pathological" high- $\mathrm{O}_{2}$ scenarios are now known, including those that involve (1) hydrogen escape from atmospheres depleted in noncondensing gases (Wordsworth and Pierrehumbert, 2014), (2) $\mathrm{CO}_{2}$ photolysis in very dry atmospheres (Gao et al., 2015), (3) atmospheres undergoing runaway water loss (Luger and Barnes, 2015), and (4) modest photochemical production of $\mathrm{O}_{2} / \mathrm{O}_{3}$ from $\mathrm{CO}_{2}$ photolysis on planets around certain types of host star (Segura et al., 2007; Domagal-Goldman et al., 2014; Harman et al., 2015). Although the diversity of mechanisms for generating high $\mathrm{O}_{2} / \mathrm{O}_{3}$ levels on lifeless worlds sounds an important cautionary note in the search for compelling biosignatures, these studies also identified a suite of contextual tools that can be used to diagnose high- $\mathrm{O}_{2}$ false positives under many circumstances (Domagal-Goldman et al., 2014; Harman et al., 2015; Schwieterman et al., 2015, 2016).

Biosignatures in reducing planetary atmospheres have been less explored (Domagal-Goldman et al., 2011; Seager et al., 2013b). This gap is important, as Earth's atmosphere has been relatively reducing-but not $\mathrm{H}_{2}$-dominated-for most of its history (e.g., Lyons et al., 2014), and it is currently unknown whether the evolution of water-splitting (oxygenic) photosynthesis should be expected to be a common phenomenon beyond our solar system. Indeed, even if energetic benefits make the evolution of oxygenic photosynthesis probable on habitable planets, this alone may not be enough. For example, Earth's atmosphere may have remained strongly reducing for 500 million years or more after the emergence of biological $\mathrm{O}_{2}$ production (Catling and Claire, 2005; Planavsky et al., 2014a). As a result, there is little a priori reason to expect that most life-bearing extrasolar worlds will be characterized by atmospheres rich in biogenic $\mathrm{O}_{2}$, particularly given our intrinsically brief timescale of observation relative to the potential timescales of planetary oxygenation.

An additional issue that has not been fully explored is that atmospheric chemistry on ocean-bearing planets can be strongly decoupled from overall surface metabolic fluxes due to internal microbial recycling within a planet's oceanic biosphere. For example, some of the largest input/output fluxes in Earth's modern biological $\mathrm{CH}_{4}$ cycle occur via the microbial production and oxidation of $\mathrm{CH}_{4}$ in deep marine sediments (Reeburgh, 2007), and this cycle is entirely decoupled from Earth's atmospheric $\mathrm{CH}_{4}$ inventory. Indeed, most of this cycling occurs through anaerobic processes in the ocean (Valentine, 2011) and can occur through a number of common electron acceptors that will not necessarily be in equilibrium with corresponding atmospheric gases (Martens and Berner, 1977; Hoehler et al., 1994; Regnier et al., 2011; Sivan et al., 2011; Deutzmann et al., 2014; Riedinger et al., 2014). As a result, internal recycling by ocean biospheres may inhibit the development or erode the stability of atmospheric biosignatures despite large production rates of biosignature gases. Such oceanic filtering of atmospheric biosignatures could in principle occur on a wide range of ocean-bearing silicate planets and in many cases will be an important process even on reducing planetary surfaces.

A second example is provided by the possibility of a cryptic oxygenic biosphere. In Earth's oceans, slow air-sea exchange of $\mathrm{O}_{2}$ relative to high local rates of biological production in the surface waters can result in large regions of the surface ocean that are strongly out of equilibrium with atmospheric $p \mathrm{O}_{2}$, by as much as a factor of $\sim 10^{4}$ (Kasting, 1991; Olson et al., 2013; Reinhard et al., 2013a, 2016). Thus, despite vigorous biological $\mathrm{O}_{2}$ production in the shallowest oceanic environments, a planetary atmosphere can remain pervasively reducing as a result of either low globally integrated surface fluxes or elevated atmospheric sinks (or some combination). Such planets may be capable of accumulating significant quantities of reduced biosignature gases but will be false negatives for the presence of oxygenic photosynthesis and will have limited capacity for preservation and detection of associated oxidized biosignatures gases (e.g., $\mathrm{O}_{3}, \mathrm{~N}_{2} \mathrm{O}$ ).

As a proof on concept, we briefly summarize the remote detectability of $\mathrm{O}_{2} / \mathrm{O}_{3}, \mathrm{CH}_{4}$, and the $\mathrm{O}_{2}-\mathrm{CH}_{4}$ disequilibrium throughout Earth's history. Our analysis suggests that the $\mathrm{O}_{2}-\mathrm{CH}_{4}$ disequilibrium approach would have failed for most of Earth's history, particularly for observations at low to moderately high spectral resolving power $(R \leq 10,000)$. In addition, it is possible that $\mathrm{O}_{2} / \mathrm{O}_{3}$ may only have been applicable as a potential biosignature during the last $\sim 10 \%$ of Earth's lifetime. As a result, most of our planet's history may have been characterized by either high abundances of a single biogenic gas that can also have significant abiotic sources $\left(\right.$ e.g., $\left.\mathrm{CH}_{4}\right)$ or by a cryptic biosphere that was widespread and active at the surface but remained ultimately unrepresented in the detectable composition of Earth's atmosphere. Finally, we argue that cryptic biospheres may be a particularly acute problem on ocean-bearing planets, with the implication that many of the most favorable planetary hosts for surface biospheres will also have high potential for attenuation of atmospheric biosignatures. 


\section{Evolution of Atmospheric $\mathrm{O}_{2} / \mathrm{O}_{3}$ during Earth's History}

The most compelling quantitative insights into atmospheric $\mathrm{O}_{2}$ abundance during Archean time ( $\left.\sim 3.8-2.5 \mathrm{Ga}\right)$ come from the observation of large non-mass-dependent sulfur isotope anomalies in sulfide and sulfate minerals deposited in coeval marine sediments (Farquhar et al., 2000, 2001; reviewed in Johnston, 2011). When interpreted in the context of photochemical models (Pavlov and Kasting, 2002; Ono et al., 2003; Zahnle et al., 2006; Ueno et al., 2009), the presence of these isotopic anomalies implies a ground-level atmospheric $\mathrm{pO}_{2}$ value that was below $10^{-5}$ times the present atmospheric level (PAL) and more likely below $\sim 10^{-7}$ PAL (e.g., Claire et al., 2006; Zahnle et al., 2006). Though there is some evidence for transient periods of elevated $\mathrm{pO}_{2}$ during the Archean (Anbar et al., 2007; Reinhard et al., 2009; Kendall et al., 2015), these deviations are poorly understood from a quantitative standpoint, and the overall background state during Archean time appears to have been one of exceptionally low atmospheric $\mathrm{O}_{2}$. The sulfur isotope anomalies fingerprinting extremely low atmospheric $\mathrm{O}_{2}$ disappear relatively rapidly during the Great Oxidation Event (GOE) of the early Paleoproterozoic (Holland,
2002; Luo et al., 2016) and are not seen again in typical marine sedimentary rocks for the remainder of Earth's history (Fig. 1).

Unfortunately, the rather extreme sensitivity of the sulfur isotope system to very low levels of $\mathrm{O}_{2}$ in the atmosphere makes it unfeasible to quantitatively diagnose changes in atmospheric composition once $\mathrm{pO}_{2}$ increased above $\sim 1-2$ ppmv during the GOE. As a result, atmospheric $\mathrm{O}_{2}$ levels for most of the subsequent $\sim 2.5$ billion years of Earth's history are rather poorly constrained. There is some evidence from the geochemical record for a transient, though protracted, rise in atmospheric $\mathrm{pO}_{2}$ during the Paleoproterozoic (Schröder et al., 2008; Planavsky et al., 2012; Partin et al., 2013; Canfield et al., 2015), perhaps to levels that would have rivaled those of the modern Earth (Fig. 1). However, this evidence remains somewhat fragmentary at present and is difficult to evaluate quantitatively.

Nevertheless, a number of geochemical records point to low atmospheric $\mathrm{pO}_{2}$ for extended periods of Earth's history well after the GOE. For example, the apparent loss of Fe (and in some cases $\mathrm{Mn}$ ) as dissolved reduced species from paleosols (ancient weathering profiles) during some periods of the Proterozoic (Holland, 1984) and the general lack of significant chromium $(\mathrm{Cr})$ isotope fractionation in marine

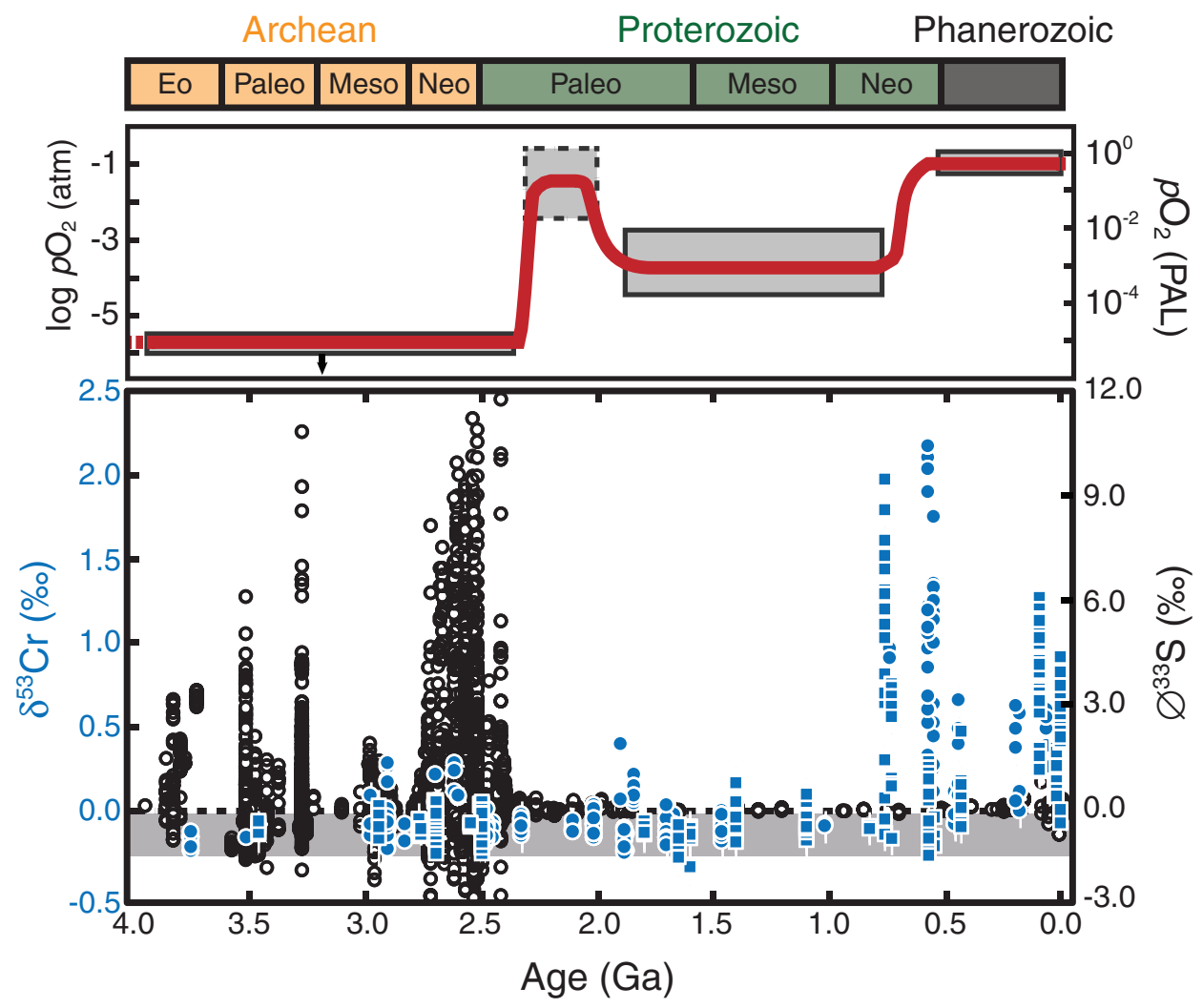

FIG. 1. Atmospheric $\mathrm{O}_{2}$ on Earth through time (upper) and select geochemical proxies for atmospheric $p \mathrm{O}_{2}$ (lower). In the upper panel, shaded boxes show approximate ranges based on geochemical proxy reconstructions, while the red curve shows one possible trajectory through time. In the lower panel, open circles show the magnitude of non-mass-dependent sulfur isotope (NMD-S) anomalies, shown as $\Delta^{33} \mathrm{~S}$ (see Johnston, 2011) and compiled as in Reinhard et al. (2013b). Filled blue symbols show chromium (Cr) isotope fractionations from iron-rich and siliciclastic marine sedimentary rocks throughout Earth's history (Cole et al., 2016). We show these particular proxies in order to optically emphasize the three major periods of Earth's history discussed here: the Archean $(\sim 3.8-2.5 \mathrm{Ga})$, the Proterozoic $(\sim 2.5-0.5 \mathrm{Ga})$, and the Phanerozoic ( $\sim 500 \mathrm{Ma}$ to the present). See Lyons et al. (2014) for a more in-depth recent discussion of atmospheric $\mathrm{O}_{2}$ proxies and evolution through time. 
Table 1. Atmospheric $P \mathrm{O}_{2}$ AND $P \mathrm{CH}_{4}$ Values FOR DifFERENT GeOlogical EPOCHS USED in Our Spectral Calculations

\begin{tabular}{|c|c|c|c|c|c|}
\hline \multicolumn{2}{|l|}{ Age } & \multicolumn{2}{|c|}{$\mathrm{p} O_{2}(P A L)$} & \multicolumn{2}{|c|}{$\mathrm{p} C \mathrm{H}_{4}(\mathrm{ppmv})$} \\
\hline Stratigraphic & $M a$ & Low & High & Low & High \\
\hline Arcl & $3800-2500$ & - & $10^{-5}$ & $10^{2}$ & $10^{3}$ \\
\hline Lomagundi & $2200-2000$ & $10^{-2}$ & 2.0 & 0.7 & 6 \\
\hline mid-Proterozoic & $1800-800$ & $10^{-3.3}$ & $10^{-2}$ & 1 & 20 \\
\hline Phanerozoic & $543-0$ & 0.25 & 1.4 & 0.7 & 6 \\
\hline
\end{tabular}

Values for $p \mathrm{O}_{2}$ are approximated according to Rye and Holland (1998), Pavlov and Kasting (2002), Bergman et al. (2004), Glasspool and Scott (2010), Crowe et al. (2013), Lyons et al. (2014), Planavsky et al. (2014b), and Tang et al. (2016). Values for $p \mathrm{CH}_{4}$ are approximated according to Pavlov et al. (2000, 2003), Claire et al. (2006), Zahnle et al. (2006), Catling et al. (2007), Bartdorff et al. (2008), and Olson et al. (2016).

sediments (Planavsky et al., 2014b; Cole et al., 2016) are both consistent with very low atmospheric $p \mathrm{O}_{2}$ between $\sim 1.8$ and $0.8 \mathrm{Ga}$ (Fig. 1). Such low $p \mathrm{O}_{2}$ conditions are also echoed in the numerous indicators of low oxygen in the deep and shallow ocean during this period (Planavsky et al., 2011; Poulton and Canfield, 2011; Reinhard et al., 2013c; Tang et al., 2016). However, a smaller atmospheric $\mathrm{O}_{2}$ inventory during this period carries with it the potential for somewhat unstable behavior (e.g., Planavsky et al., 2014b), and there is proxy evidence for potential short-term fluctuations in atmospheric $\mathrm{pO}_{2}$ between $\sim 1.8$ and $0.8 \mathrm{Ga}(e . g$., Sperling et al., 2014; Gilleaudeau et al., 2016).

Geochemical records during the Neoproterozoic $(\sim 1000$ $541 \mathrm{Ma}$ ) suggest significant ocean-atmosphere redox shifts just prior to the Sturtian glacial epoch at ca. $720 \mathrm{Ma}$ (Planavsky et al., 2014b; Thomson et al., 2015) followed by a potentially highly dynamic interval leading up to the PrecambrianCambrian boundary at $541 \mathrm{Ma}$ (Sahoo et al., 2016). Atmospheric $\mathrm{pO}_{2}$ during the earliest Paleozoic ( 543-400 Ma), though not particularly well constrained at present, was likely higher than that of the late Proterozoic but well below modern
(Bergman et al., 2004; Dahl et al., 2010; Lyons et al., 2014). Thereafter, the charcoal record strongly suggests that $\mathrm{pO}_{2}$ values during most of the last $\sim 400$ million years have been above $\sim 50 \%$ PAL (e.g., Cope and Chaloner, 1980; Chaloner, 1989), making $\mathrm{O}_{2}$ a dominant constituent of Earth's atmosphere for most of the last half-billion years (Fig. 1; Table 1).

From a practical perspective, the detection of $\mathrm{O}_{2}$ can be achieved via proxy by searching for signs of $\mathrm{O}_{3}$. On the modern Earth, stratospheric $\mathrm{O}_{3}$ is ultimately derived from the photolysis of atmospheric $\mathrm{O}_{2}$, which generates oxygen atoms that subsequently combine with $\mathrm{O}_{2}$ molecules to yield $\mathrm{O}_{3}$ (the first two of the so-called "Chapman reactions"):

$$
\begin{gathered}
\mathrm{O}_{2}+h \nu \rightarrow \mathrm{O}+\mathrm{O}(\lambda<242 \mathrm{~nm}) \\
\mathrm{O}+\mathrm{O}_{2}+M \rightarrow \mathrm{O}_{3}+M
\end{gathered}
$$

where $M$ is any inert molecule that can absorb the energy of the excited $\mathrm{O}_{3}$ molecule following collision between $\mathrm{O}$ and $\mathrm{O}_{2}$ and eventually dissipate it as heat. The column abundance of atmospheric ozone $\left(\mathrm{O}_{3}\right)$ shows a nonlinear dependence on the $\mathrm{O}_{2}$ content of Earth's atmosphere in 1-D photochemical models (Kasting and Donahue, 1980). In addition, both the altitude and overall abundance of peak $\mathrm{O}_{3}$ increase with ground-level atmospheric $p \mathrm{O}_{2}$ (Fig. 2A).

Considering this in light of the geochemical records discussed above, it is possible that for much of Earth's history atmospheric $\mathrm{O}_{3}$ abundance was extremely low. We can estimate the effects of this by using the characteristics of $\mathrm{O}_{3}$ profiles generated by a suite of 1-D photochemical models (Kasting and Donahue, 1980) to calculate peak $\mathrm{O}_{3}$ levels in Earth's atmosphere as a function of ground-level $p \mathrm{O}_{2}$ (Fig. 2B). The results of this exercise suggest that peak midProterozoic atmospheric $\mathrm{O}_{3}$ would have been $\sim 0.1-1 \mathrm{ppmv}$ based on the ground-level $p \mathrm{O}_{2}$ values estimated for this time interval (e.g., $p \mathrm{O}_{2} \sim 0.1-1 \%$ PAL) and many orders of magnitude below this during the Archean. However, during most of the Phanerozoic, and potentially some periods of the Paleoproterozoic, atmospheric $\mathrm{O}_{3}$ would have been present at values approaching that of the modern Earth (Table 1).
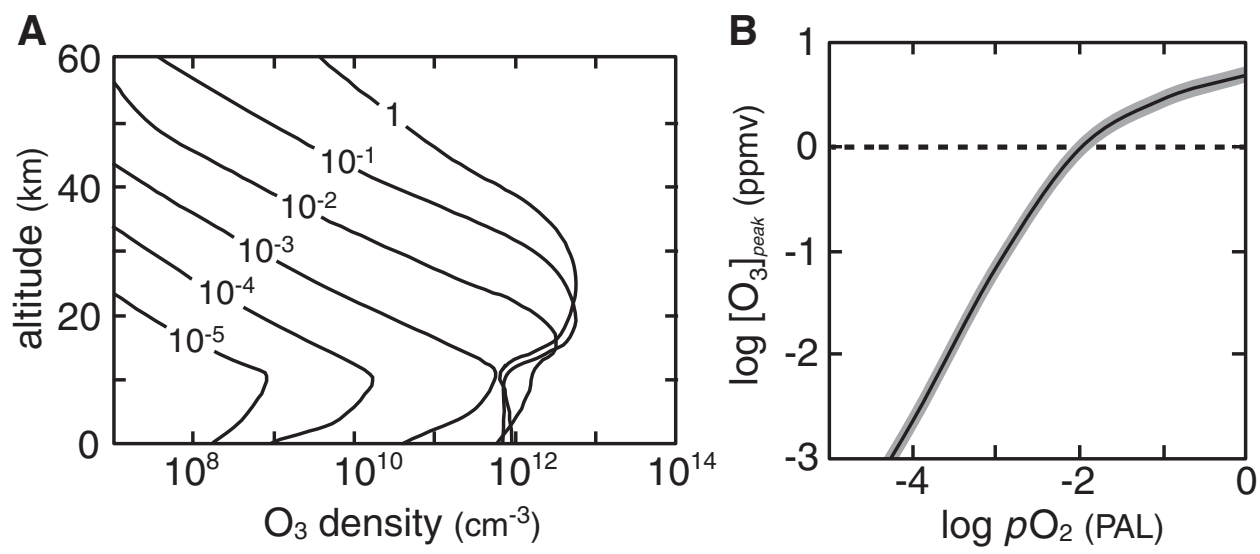

FIG. 2. Shown in (A) are number densities for atmospheric ozone $\left(\mathrm{O}_{3}\right)$ as a function of altitude calculated from a 1-D photochemical model (after Kasting and Donahue, 1980) at different atmospheric $p \mathrm{O}_{2}$ values (relative to PAL). The calculations assume a solar zenith angle of $45^{\circ}$. Shown in (B) are calculated values of peak atmospheric $\mathrm{O}_{3}$ as a function of ground-level $\mathrm{pO}_{2}$ according to the results of Kasting and Donahue (1980). The calculations assume an atmospheric scale height of $7 \mathrm{~km}$ and a range of temperatures between 200 and $240 \mathrm{~K}$ but are not particularly sensitive to either of these values. The horizontal dashed line denotes a peak $\mathrm{O}_{3}$ level of 1 ppmv (see text). 

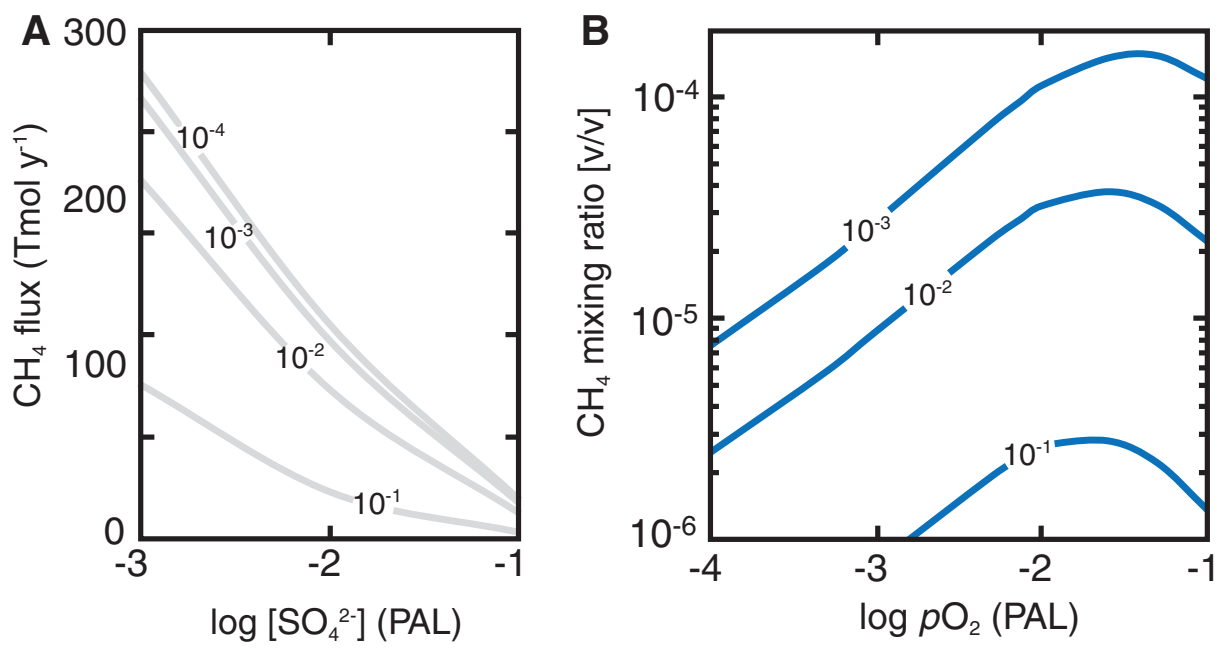

FIG. 3. Representative results from an intermediate-complexity Earth system model of the ocean-atmosphere $\mathrm{O}_{2}-\mathrm{O}_{3}-\mathrm{CH}_{4}$ cycle. Shown (A) are net biospheric $\mathrm{CH}_{4}$ fluxes to the atmosphere as a function of global average marine sulfate concentration $\left(\left[\mathrm{SO}_{4}{ }^{2-}\right]\right)$, with contours labeled according to atmospheric $\mathrm{pO}_{2}$ value (relative to PAL). Shown in (B) are steady-state atmospheric $\mathrm{CH}_{4}$ mixing ratios as a function of atmospheric $p \mathrm{O}_{2}$, with contours labeled according to marine $\left[\mathrm{SO}_{4}{ }^{2-}\right]\left(\mathrm{relative} \mathrm{to}^{2}\right.$ the present oceanic level, POL). Simulations performed under the same default conditions as those in Olson et al. (2016).

\section{Evolution of Atmospheric $\mathrm{CH}_{4}$ during Earth's History}

Atmospheric $\mathrm{O}_{2} / \mathrm{O}_{3}$ abundances estimated based on the ground-level $p \mathrm{O}_{2}$ values discussed above would have had an important impact on another key biosignature gas - methane $\left(\mathrm{CH}_{4}\right)$. The relationship between the atmospheric lifetime of $\mathrm{CH}_{4}$ and the $\mathrm{O}_{2}$ content of Earth's atmosphere is complex and somewhat counterintuitive. As atmospheric $p \mathrm{O}_{2}$ drops from 1 to $10^{-1} \mathrm{PAL}$, the atmospheric lifetime of $\mathrm{CH}_{4}$ increases as a result of decreasing rates of $\mathrm{CH}_{4}$ destruction in the atmosphere by hydroxyl radicals $(\mathrm{OH})$. However, once $\mathrm{pO}_{2}$ drops below $\sim 10^{-2}$ PAL the atmospheric lifetime of $\mathrm{CH}_{4}$ decreases sharply. This latter behavior arises as a result of increased photochemical production of tropospheric $\mathrm{OH}$ as UV shielding by $\mathrm{O}_{3}$ decreases (Kasting and Donahue, 1980; Pavlov et al., 2000, 2003; Pavlov and Kasting, 2002). An additional complexity is that the atmospheric lifetime of $\mathrm{CH}_{4}$ is also a highly nonlinear function of its source fluxes from the biosphere and solid Earth (Pavlov et al., 2003), which means that potential oceanic sinks for $\mathrm{CH}_{4}$ must also be considered in any attempt to diagnose atmospheric $p \mathrm{CH}_{4}$. Because the biospheric production and consumption fluxes of $\mathrm{CH}_{4}$ are also directly or indirectly linked to atmospheric $\mathrm{O}_{2}$ levels via the availability of oxidants at a planet's surface (e.g., $\mathrm{O}_{2}, \mathrm{Fe}^{3+}, \mathrm{SO}_{4}{ }^{2-}$ ), the quantitative relationship between atmospheric $\mathrm{O}_{2}$ and $\mathrm{CH}_{4}$ will be extremely complex on ocean-bearing silicate planets.

Though there is at present no available geochemical proxy for ancient atmospheric $\mathrm{CH}_{4}$ levels, a number of recent studies have attempted to explicitly model the effect of metabolic $\mathrm{CH}_{4}$ consumption on surface fluxes and atmospheric $p \mathrm{CH}_{4}$ (Claire et al., 2006; Catling et al., 2007; Beal et al., 2011; Daines and Lenton, 2016; Olson et al., 2016). The most recent attempt includes both aerobic and anaerobic microbial oxidation of $\mathrm{CH}_{4}$ within a 3-D model of ocean biogeochemistry coupled to a parameterized $\mathrm{O}_{2}-\mathrm{O}_{3}-\mathrm{CH}_{4}$ photochemical scheme (Olson et al., 2016). Overall, the results of this work suggest that atmospheric $\mathrm{CH}_{4}$ levels are extremely sensitive to concentrations of seawater sulfate $\left(\mathrm{SO}_{4}{ }^{2-}\right)$. As a result, at atmospheric $p \mathrm{O}_{2}$ values and marine $\mathrm{SO}_{4}{ }^{2-}$ levels characteristic of the Proterozoic, net biogenic $\mathrm{CH}_{4}$ fluxes would have been strongly attenuated such that atmospheric $p \mathrm{CH}_{4}$ was unlikely to have been significantly higher than 1-10 ppmv (Fig. 3; Olson et al., 2016). However, given recent estimates of Archean seawater $\mathrm{SO}_{4}{ }^{2-}$ levels (Crowe et al., 2014), it is likely that biogenic $\mathrm{CH}_{4}$ fluxes to the atmosphere would have been much higher during this period. Combined with much lower atmospheric $p \mathrm{O}_{2}$, these larger fluxes could potentially have led to $\mathrm{Ar}$ chean atmospheric $p \mathrm{CH}_{4}$ values on the order of $\sim 10^{2}$ to $10^{3}$ ppmv (Pavlov et al., 2000; Claire et al., 2006; Zahnle et al., 2006; Catling et al., 2007).

\section{Remote Detectability of $\mathrm{O}_{2}-\mathrm{O}_{3}-\mathrm{CH}_{4}$ Biosignatures throughout Earth's History}

The actual detectability of any gas in a future exoplanet observation will be a combined function of the abundance of that gas in the atmosphere, the observing parameters (such as distance, stellar host type, background noise, etc.), and the instrumentation with which the observation is made (see, e.g., Robinson et al., 2016). Here, we conduct a qualitative assessment of the potential detectability of $\mathrm{O}_{2}, \mathrm{O}_{3}$, and $\mathrm{CH}_{4}$ through geological time by generating synthetic directimaging spectra based on scaling a modern midlatitude Earth atmosphere profile (Schwieterman et al., 2015) to the evolving gas abundances throughout Earth's history (Table 1). We use the Spectral Mapping Atmosphere Radiative Transfer Model (SMART; Meadows and Crisp, 1996; Crisp 1997), which is well validated by remote observations of the whole Earth (Robinson et al., 2011, 2014), Venus (Arney et al., 2014), and Mars (Tinetti et al., 2005) and has been previously used in spectral studies of the Archean Earth (Arney et al., 2016). We focus on the $\mathrm{O}_{3}$ UV HartleyHuggins bands (centered at $\sim 0.25 \mu \mathrm{m}$ ), the $\mathrm{O}_{2}$ Fraunhofer 


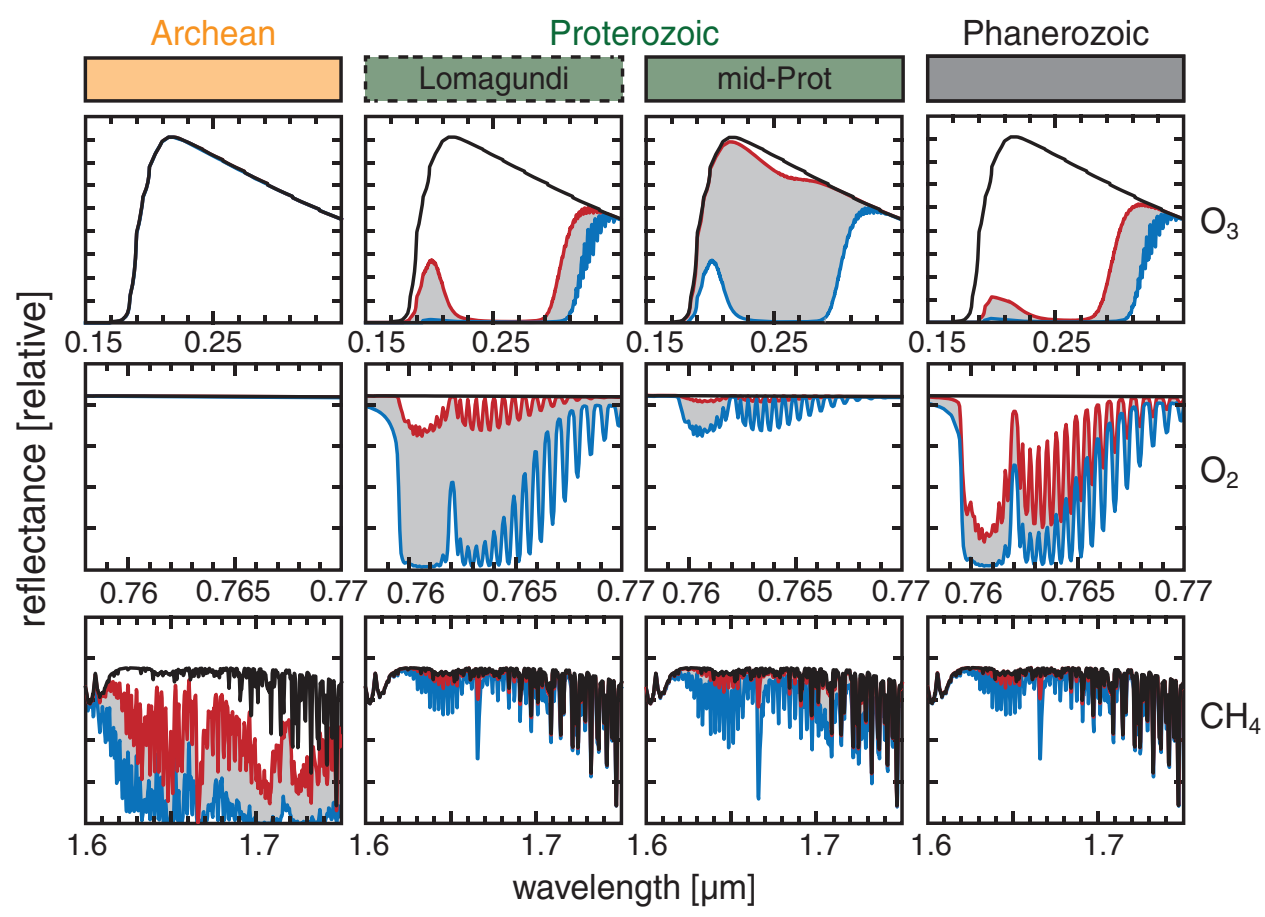

FIG. 4. Reflectance spectra of selected $\mathrm{O}_{2}, \mathrm{O}_{3}$, and $\mathrm{CH}_{4}$ bands as a function of geological epoch. Lower abundance limits are given in red, upper limits are given in blue, and the region between these limits is shaded gray. The black line represents the case with no absorption by $\mathrm{O}_{2}, \mathrm{O}_{3}$, or $\mathrm{CH}_{4}$. Limits are representative of both uncertainties in atmospheric abundance and variability of those abundances over the course of each epoch (Table 1). Values for peak atmospheric $\mathrm{O}_{3}$ are calculated as a function of ground-level $\mathrm{pO}_{2}$ according to the results of Kasting and Donahue (1980). The resolution of each spectrum is $1 \mathrm{~cm}^{-1}$, which is approximately $\Delta \lambda=6.25 \times 10^{-6} \mu \mathrm{m}$ at $0.25 \mu \mathrm{m}, \Delta \lambda=5.78 \times 10^{-5} \mu \mathrm{m}$ at $0.76 \mu \mathrm{m}$, and $\Delta \lambda=2.72 \times 10^{-4} \mu \mathrm{m}$ at $1.65 \mu \mathrm{m}$. We used a solar zenith angle of $60^{\circ}$ to approximate a disk-average. Note that reflectances are arbitrarily scaled to provide a qualitative assessment of potential detectability.

A band $(0.76 \mu \mathrm{m})$, and the $1.65 \mu \mathrm{m} \mathrm{CH}_{4}$ band as a function of geological epoch (Fig. 4). These bands were chosen in part because they will likely be included in the instrumentation suite of future direct-imaging telescopes (e.g., Dalcanton et al., 2015) and because mid-IR direct imaging of exoplanets is unlikely for the intermediate future.

Molecular oxygen $\left(\mathrm{O}_{2}\right)$ has no significant spectral features at mid-IR wavelengths, but it has three significant features in the optical range (Des Marais et al., 2002). These are the so-called "Fraunhofer" A and B bands (at 0.76 and $0.69 \mu \mathrm{m}$, respectively), along with an additional feature at $1.26 \mu \mathrm{m}$. Of these, the Fraunhofer A band is the most prominent but is likely to have appreciable depth only at atmospheric $\mathrm{pO}_{2}$ levels of $\sim 1 \%$ or higher (Fig. 4; Des Marais et al., 2002). Thus, direct detection or quantification of molecular oxygen $\left(\mathrm{O}_{2}\right)$ would have been very difficult for much of Earth's history, other than during a transient period of the Paleoproterozoic and during most of the last $\sim 500$ million years (Figs. 1 and 4).

Ozone has a number of spectral features in the IR, visible, and UV range, including a strong feature at $9.7 \mu \mathrm{m}$, the socalled "Chappuis" bands between 0.5 and $0.7 \mu \mathrm{m}$, and the "Hartley-Huggins" bands at $\sim 0.35-0.2 \mu \mathrm{m}$ (Des Marais et al., 2002; Domagal-Goldman et al., 2014). The most promising of these from a detection standpoint is the combined Hartley-Huggins band in the near-UV centered at $\sim 0.25 \mu \mathrm{m}$ (Fig. 4), which is the most sensitive to small $\mathrm{O}_{2}$ abundance and saturates at $\mathrm{O}_{3}$ fractions of $<1 \mathrm{ppmv}$. This band is also important because it lies within the proposed instrument range for space-based telescope missions currently under consideration (Dalcanton et al., 2015; Mennesson et al., 2016).

Peak $\mathrm{O}_{3}$ abundances near the upper range of Proterozoic estimates would potentially have been a promising candidate for detection via the UV-Hartley band, but even this feature may have been challenging to observe at the lower end of $\mathrm{pO}_{2}$ estimates. Combined with atmospheric $p \mathrm{O}_{2}$ values orders of magnitude below this during the Archean, atmospheric $\mathrm{O}_{2}$ (and possibly $\mathrm{O}_{3}$ ) would perhaps have been difficult to detect remotely in Earth's atmosphere for most of its history. A potential exception to this early signal gap exists in the " $\mathrm{O}_{2}$ overshoot" hypothesized for the Paleoproterozoic (see above), representing the fascinating possibility of a transiently detectable $\mathrm{O}_{2}$-rich biogenic atmosphere during Earth's early history followed by over a billion years of predominantly undetectable $\mathrm{O}_{2} / \mathrm{O}_{3}$ levels. Possible shifts to more elevated $\mathrm{pO}_{2}$ on shorter timescales between $\sim 1.8$ and $0.8 \mathrm{Ga}$ (e.g., Planavsky et al., 2014b; Sperling et al., 2014; Gilleaudeau et al., 2016) should also be explored for their plausibility as biosignature windows.

Methane has a number of features in the mid-IR and visible to near-IR ranges, including five weak features between 0.6 and $1.0 \mu \mathrm{m}$, two at 1.65 and $2.4 \mu \mathrm{m}$, and a significant feature at $\sim 7.7-8.2 \mu \mathrm{m}$. The $1.65 \mu \mathrm{m} \mathrm{CH}_{4}$ band would likely have been visible during Archean time (Fig. 4), but the 0.6-1.0 $\mu \mathrm{m}$ features are only expected to have appreciable depth at $p \mathrm{CH}_{4}$ 
above $\sim 10^{3}$ ppmv (Des Marais et al., 2002). In any case, in light of the model results discussed above it is possible that atmospheric $\mathrm{CH}_{4}$ would have been a challenging detection for the last $\sim 2.5$ billion years of Earth's history (e.g., subsequent to the GOE), at least via low- to moderate-resolution spectroscopy. However, the very low atmospheric $p \mathrm{O}_{2}$ and oceanic $\mathrm{SO}_{4}{ }^{2-}$ concentrations reconstructed for Archean time leave open the possibility that $\mathrm{CH}_{4}$ would have been remotely detectable in Earth's atmosphere for the better part of Earth's first $\sim 2$ billion years (Fig. 4).

\section{Discussion and Conclusions}

By combining the geochemical reconstructions, Earthsystem model results, and spectral considerations discussed above, we can place the $\mathrm{O}_{2}-\mathrm{O}_{3}-\mathrm{CH}_{4}$ disequilibrium biosignature on Earth in a broader temporal context as a possible analogue for terrestrial exoplanets. Currently available proxy and model constraints indicate that, during the Archean ( 3.8-2.5 Ga), atmospheric $\mathrm{CH}_{4}$ levels may have been generally within or above the range that would be remotely detectable. In contrast, atmospheric $\mathrm{O}_{2}$ levels were many orders of magnitude below detection of either $\mathrm{O}_{2}$ or $\mathrm{O}_{3}$, with the possible exception of pulsed $\mathrm{pO}_{2}$ increases during the late Archean (e.g., Anbar et al., 2007; Kendall et al., 2015). Combined proxy and model results indicate that, during the mid-Proterozoic, both $\mathrm{O}_{2}$ and $\mathrm{CH}_{4}$ would have been undetectable and are consistent with the possibility that $\mathrm{O}_{3}$ would have been challenging to detect. An interesting exception to this may have occurred during the Paleoproterozoic, between $\sim 2.2$ and $2.0 \mathrm{Ga}$, when atmospheric $p \mathrm{O}_{2}$ may have been elevated to detectable levels before decreasing again for over a billion years. Following possibly dynamic upheavals in ocean-atmosphere redox during the late Proterozoic, atmospheric $\mathrm{O}_{2} / \mathrm{O}_{3}$ was present at levels that would likely have been readily detectable for most of the last $\sim 500$ million years. However, results from Earth system models indicate that detection of atmospheric $\mathrm{CH}_{4}$ would have been problematic with low- to moderateresolution spectroscopy during this same period.

The realization that Earth's biosphere may have remained cryptic to conventional methods of remote detection for large periods of its history highlights the need to explore novel atmospheric biosignatures (Pilcher, 2003; DomagalGoldman et al., 2011; Seager et al., 2013a) and provides further impetus for wide-ranging and systematic exploration of possible atmospheric biosignatures for application in a range of scenarios. Our results also highlight the importance of developing contextual plausibility arguments for biogenic gases in reducing atmospheres and, in particular, the presence/absence and characteristics of exoplanetary oceans. In this light, observations of time-resolved changes in atmospheric chemistry (e.g., seasonality) that can be firmly linked to quantitative models for biotic and abiotic sources will be important to consider. For example, although there may be plausible abiotic routes to high $\mathrm{CH}_{4}$ in a reducing planetary atmosphere, it may be much more difficult to generate seasonal variations in atmospheric $p \mathrm{CH}_{4}$ without an active surface biosphere.

Our analysis suggests that a planet with a biosphere largely (or entirely) confined to the marine realm will in many cases remain invisible to remote detection as a result of biosignature filtering by ocean biogeochemistry-a difficulty that may apply to both presence/absence and thermodynamic techniques. Our analysis suggests that the possible detection of oceans at a planet's surface (Robinson et al., 2010; but see Cowan et al., 2012) is a critical piece of contextual information for validating potential atmospheric biosignatures, and that planets with terrestrial biospheres (e.g., partially or entirely subaerial in scope) may be the most readily detected and characterized because of their more direct geochemical exchange with the overlying atmosphere. Ironically, in some cases planets that are very conducive to the development and maintenance of a pervasive biosphere, with large inventories of $\mathrm{H}_{2} \mathrm{O}$ and extensive oceans, may at times be the most difficult to characterize via conventional biosignature techniques.

Although our results are broadly applicable to Earthanalog planets orbiting Sun-like stars, additional work will be necessary to determine the extent to which differences in the stellar environment may impact the buildup of $\mathrm{O}_{2}$ and $\mathrm{CH}_{4}$ (e.g., Loyd et al., 2016; Meadows et al., 2016), while also considering the effects of ocean chemistry, as we have done here. Nevertheless, our work further stresses the importance of including and refining UV observations for exploration of potentially habitable exoplanets, since it is quite plausible that Proterozoic Earth analogues would have detectable $\mathrm{O}_{3}$ without spectrally apparent $\mathrm{O}_{2}$. Moreover, high-resolution spectroscopy $(R>20,000)$, coupled with high-contrast imaging, may provide a promising avenue for detecting modern Earth-like $\mathrm{CH}_{4}$ abundances on an exoplanet (e.g., Snellen et al., 2015), though the feasibility of this technique has yet to be conclusively demonstrated. We would recommend investigation of this technique as perhaps the only plausible approach toward observing the $\mathrm{O}_{2}-\mathrm{CH}_{4}$ biosignature couple in true Earth analogues. More broadly, our analysis highlights the importance of including a rigorous understanding of ocean biogeochemistry into models of biosignature production and preservation on exoplanets and affirms that critical insights into the evolution of atmospheric biosignatures on Earth-like planets can be provided by better understanding Earth's dynamic history.

\section{Acknowledgments}

C.T.R. and T.W.L. acknowledge support from the NASA Astrobiology Institute. C.T.R. acknowledges support from the Alfred P. Sloan Foundation. E.W.S. acknowledges support from the NASA Astrobiology Institute Director's Discretionary Fund and the NASA Postdoctoral Program, administered by the Universities Space Research Association. This work benefited from the use of advanced computational, storage, and networking infrastructure provided by the Hyak supercomputer system at the University of Washington.

\section{References}

Akeson, R.L., Chen, X., Ciardi, D., Crane, M., Good, J., Harbut, M., Jackson, E., Kane, S.R., Laity, A.C., Leifer, S., Lynn, M., McElroy, D.L., Papin, M., Plavchan, P., Ramírez, S.V., Rey, R., von Braun, K., Wittman, M., Abajian, M., Ali, B., Beichman, C., Beekley, A., Berriman, G.B., Berukoff, S., Bryden, G., Chan, B., Groom, S., Lau, C., Payne, A.N., Regelson, M., Saucedo, M., Schmitz, M., Stauffer, J., Wyatt, P., 
and Zhang, A. (2013) The NASA Exoplanet Archive: data and tools for exoplanet research. Publ Astron Soc Pac 125: 989-999.

Anbar, A.D., Duan, Y., Lyons, T.W., Arnold, G.L., Kendall, B., Creaser, R.A., Kaufman, A.J., Gordon, G.W., Scott, C., Garvin, J., and Buick, R. (2007) A whiff of oxygen before the Great Oxidation Event? Nature 317:1903-1906.

Arney, G., Meadows, V., Crisp, D., Schmidt, S.J., Bailey, J., and Robinson, T. (2014) Spatially resolved measurements of $\mathrm{H}_{2} \mathrm{O}, \mathrm{HCl}, \mathrm{CO}, \mathrm{OCS}, \mathrm{SO}_{2}$, cloud opacity, and acid concentration in the Venus near-infrared spectral windows. J Geophys Res: Planets 119:1860-1891.

Arney, G., Domagal-Goldman, S.D., Meadows, V.S., Wolf, E.T., Schwieterman, E., Charnay, B., Claire, M., Hébrard, E., and Trainer, M.G. (2016) The pale orange dot: the spectrum and habitability of hazy Archean Earth. Astrobiology 16:873899.

Bartdorff, O., Wallmann, K., Latif, M., and Semenov, V. (2008) Phanerozoic evolution of atmospheric methane. Global Biogeochem Cycles 22, doi:10.1029/2007GB002985.

Beal, E.J., Claire, M.W., and House, C.H. (2011) High rates of anaerobic methanotrophy at low sulfate concentrations with implications for past and present methane levels. Geobiology 9:131-139.

Bergman, N.M., Lenton, T.M., and Watson, A.J. (2004) COPSE: a new model of biogeochemical cycling over Phanerozoic time. Am J Sci 304:397-437.

Canfield, D.E., Ngombi-Pemba, L., Hammarlund, E.U., Bengston, S., Chaussidon, M., Gauthier-Lafaye, F., Meunier, A., Riboulleau, A., Rollion-Bard, C., Rouxel, O., Asael, D., Pierson-Wickmann, A., and El Albani, A. (2015) Oxygen dynamics in the aftermath of the Great Oxidation of Earth's atmosphere. Proc Natl Acad Sci USA 110:16736-16741.

Catling, D.C. and Claire, M.W. (2005) How Earth's atmosphere evolved to an oxic state: a status report. Earth Planet Sci Lett 237:1-20.

Catling, D.C., Claire, M.W., and Zahnle, K.J. (2007) Anaerobic methanotrophy and the rise of atmospheric oxygen. Philos Transact A Math Phys Eng Sci 365:1867-1888.

Chaloner, W.G. (1989) Fossil charcoal as an indicator of paleoatmospheric oxygen level. J Geol Soc London 146:171174.

Claire, M.W., Catling, D.C., and Zahnle, K.J. (2006) Biogeochemical modelling of the rise in atmospheric oxygen. Geobiology 4:239-269.

Cole, D.B., Reinhard, C.T., Wang, X., Bueguen, B., Halverson, G.P., Lyons, T.W., and Planavsky, N.J. (2016) A shale-hosted $\mathrm{Cr}$ isotope record of low atmospheric oxygen during the Proterozoic. Geology 44:555-558.

Cope, M.J. and Chaloner, W.G. (1980) Fossil charcoal as evidence of past atmospheric composition. Nature 283:647649.

Cowan, N.B., Abbot, D.S., and Voigt, A. (2012) A false positive for ocean glint on exoplanets: the latitude-albedo effect. Astrophys J 752:L3-L7.

Cowan, N.B., Greene, T., Angerhausen, D., Batalha, N.E., Clampin, M., Colón, K., Crossfield, I.J.M., Fortney, J.J., Gaudi, B.S., Harrington, J., Iro, N., Lillie, C.F., Linsky, J.L., Lopez-Morales, M., Mandell, A.M., and Stevenson, K.B. (2015) Characterizing transiting planet atmospheres through 2025. Publ Astron Soc Pac 127:311-327.

Crisp, D. (1997) Absorption of sunlight by water vapor in cloudy conditions: a partial explanation for the cloud absorption anomaly. Geophys Res Lett 24:571-574.
Crowe, S.A., Døssing, L.N., Beukes, N.J., Bau, M., Kruger, S.J., Frei, R., and Canfield, D.E. (2013) Atmospheric oxygenation three billion years ago. Nature 501:535-538.

Crowe, S.A., Paris, G., Katsev, S., Jones, C., Kim, S.-T., Zerkle, A.L., Nomosatryo, S., Fowle, D.A., Adkins, J.F., Sessions, A.L., Farquhar, J., and Canfield, D.E. (2014) Sulfate was a trace constituent of Archean seawater. Science 346: 735-739.

Dahl, T.W., Hammarlund, E.U., Anbar, A.D., Bond, D.P.G., Gill, B.C., Gordon, G.W., Knoll, A.H., Nielsen, A.T., Schovsbo, N.H., and Canfield, D.E. (2010) Devonian rise in atmospheric oxygen correlated to the radiations of terrestrial planets and large predatory fish. Proc Natl Acad Sci USA 107:17911-17915.

Daines, S.J. and Lenton, T.M. (2016) The effect of widespread early aerobic marine ecosystems on methane cycling and the Great Oxidation. Earth Planet Sci Lett 434:42-51.

Dalcanton, J., Seager, S., Aigrain, S., Hirata, C., Battel, S., Mather, J., Brandt, N., Postman, M., Conroy, C., Redding, D., Feinberg, L., Schiminiovich, D., Gezari, S., Stahl, H.P., Guyon, O., Tumilinson, J., and Harris, W. (2015) From Cosmic Birth to Living Earths: A Visionary Space Telescope for $U V$ Optical-NearIR Astronomy, Association of Universities for Research in Astronomy, Washington, DC. Available online at http://www.hdstvision.org/report

Deming, D., Seager, S., Winn, J., Miller-Ricci, E., Clampin, M., Lindler, D., Greene, T., Charbonneau, D., Laughlin, G., Ricker, G., Latham, D., and Enninco, K. (2009) Discovery and characterization of transiting super Earths using an allsky transit survey and follow-up by the James Webb Space Telescope. Publ Astron Soc Pac 121:952-967.

Des Marais, D.J., Harwit, M.O., Jucks, K.W., Kasting, J.F., Lin, D.N., Lunine, J.I., Schneider, J., Seager, S., Traub, W.A., and Woolf, N.J. (2002) Remote sensing of planetary properties and biosignatures on extrasolar terrestrial planets. Astrobiology 2:153-181.

Deutzmann, J.S., Stief, P., Brandes, J.A., and Schink, B. (2014) Anaerobic methane oxidation coupled to denitrification is the dominant methane sink in a deep lake. Proc Natl Acad Sci USA 111:18273-18278.

Domagal-Goldman, S.D., Meadows, V.S., Claire, M.W., and Kasting, J.F. (2011) Using biogenic sulfur gases as remotely detectable biosignatures on anoxic planets. Astrobiology 11: 419-441.

Domagal-Goldman, S.D., Segura, A., Claire, M.W., Robinson, T.D., and Meadows, V.S. (2014) Abiotic ozone and oxygen in atmospheres similar to prebiotic Earth. Astrophys J 792, doi:10.1088/0004-637X/792/2/90.

Farquhar, J., Bao, H., and Thiemens, M. (2000) Atmospheric influence of Earth's earliest sulfur cycle. Science 289:756758.

Farquhar, J., Savarino, J., Airieau, S., and Thiemens, M. (2001) Observation of wavelength-sensitive mass-independent sulfur isotope effects during $\mathrm{SO}_{2}$ photolysis: implications for the early atmosphere. J Geophys Res 106:1-11.

Gao, P., Hu, R., Robinson, T.D., Li, C., and Yung, Y.L. (2015) Stability of $\mathrm{CO}_{2}$ atmospheres on desiccated $\mathrm{M}$ dwarf exoplanets. Astrophys J 806, doi:10.1088/0004-637X/806/2/ 249.

Gardner, J.P., Mather, J.C., Clampin, M., Doyon, R., Greenhouse, M.A., Hammel, H.B., Hutchings, J.B., Jakobsen, P., Lilly, S.J., Long, K.S., Lunine, J.I., McCaughrean, M.J., Mountain, M., Nella, J., Rieke, G.H., Rieke, M.J., Rix, H., Smith, E.P., Sonneborn, G., Stiavelli, M., Stockman, H.S., 
Windhorst, R.A., and Wright, G.S. (2006) The James Webb Space Telescope. Space Sci Rev 123:485-606.

Gilleaudeau, G.J., Frei, R., Kaufman, A.J., Kah, L.C., Azmy, K., Bartley, J.K., Chernyavskiy, P., and Knoll, A.H. (2016) Oxygenation of the mid-Proterozoic atmosphere: clues from chromium isotopes in carbonates. Geochemical Perspectives Letters 2:178-187.

Glasspool, I.J. and Scott, A.C. (2010) Phanerozoic concentrations of atmospheric oxygen reconstructed from sedimentary charcoal. Nat Geosci 3:627-630.

Harman, C.E., Schwieterman, E.W., Schottelkotte, J.C., and Kasting, J.F. (2015) Abiotic $\mathrm{O}_{2}$ levels on planets around F, G, $\mathrm{K}$, and $\mathrm{M}$ stars: possible false positives for life? Astrophys $J$ 812, doi:10.1088/0004-637X/812/2/137.

Hitchcock, D.R. and Lovelock, J.E. (1967) Life detection by atmospheric analysis. Icarus 7:149-159.

Hoehler, T.M., Alperin, M.J., Albert, D.B., and Martens, C.S. (1994) Field and laboratory studies of methane oxidation in an anoxic marine sediment: evidence for a methanogensulfate reducer consortium. Global Biogeochem Cycles 8: 451-463.

Holland, H.D. (1984) The Chemical Evolution of the Atmosphere and Ocean, Princeton University Press, Princeton, NJ.

Holland, H.D. (2002) Volcanic gases, black smokers, and the Great Oxidation Event. Geochim Cosmochim Acta 66:38113826.

Johnston, D.T. (2011) Multiple sulfur isotopes and the evolution of Earth's surface sulfur cycle. Earth-Science Reviews 106: 161-183.

Kaltenegger, L., Traub, W.A., and Jucks, K.W. (2007) Spectral evolution of an Earth-like planet. Astrophys J 658:598-616.

Kasting, J.F. (1991) Box models for the evolution of atmospheric oxygen. Glob Planet Change 97:125-131.

Kasting, J.F. and Donahue, T.M. (1980) The evolution of atmospheric ozone. J Geophys Res: Oceans and Atmospheres 85:3255-3263.

Kendall, B., Creaser, R.A., Reinhard, C.T., Lyons, T.W., and Anbar, A.D. (2015) Transient episodes of mild environmental oxygenation and oxidative continental weathering during the late Archean. Sci Adv 1, doi:10.1126/sciadv.1500777.

Krissanson-Totton, J., Bergsman, D.S., and Catling, D.C. (2016) On detecting biospheres from chemical thermodynamic disequilibrium in planetary atmospheres. Astrobiology 16:39-67.

Lovelock, J.E. (1965) A physical basis for life detection experiments. Nature 207:568-570.

Loyd, R.O.P., France, K., Youngblood, A., Schneider, C., Brown, A., Hu, R., Linsky, J., Froning, C.S., Redfield, S., Rugheimer, S., and Tian, F. (2016) The MUSCLES Treasury Survey. III. X-ray to infrared spectra of $11 \mathrm{M}$ and $\mathrm{K}$ stars hosting planets. Astrophys J 824, doi:10.3847/0004-637X/ $824 / 2 / 102$

Luger, R. and Barnes, R. (2015) Extreme water loss and abiotic $\mathrm{O}_{2}$ buildup on planets throughout the habitable zones of $\mathrm{M}$ dwarfs. Astrobiology 15:119-143.

Luo, G., Ono, S., Beukes, N.J., Wang, D.T., Xie, S., and Summons, R.E. (2016) Rapid oxygenation of Earth's atmosphere 2.33 billion years ago. Sci $A d v$ 2, doi:10.1126/ sciadv.1600134.

Lyons, T.W., Reinhard, C.T., and Planavsky, N.J. (2014) The rise of oxygen in Earth's early ocean and atmosphere. Nature 506:307-315.
Martens, C.S. and Berner, R.A. (1977) Interstitial water chemistry of anoxic Long Island Sound sediments. 1. Dissolved gases. Limnol Oceanogr 22:10-25.

Mayor, M. and Queloz, D. (1995) A Jupiter-mass companion to a solar-type star. Nature 378:355-359.

Meadows, V.S. and Crisp, D. (1996) Ground-based nearinfrared observations of the Venus nightside: the thermal structure and water abundance near the surface. $J$ Geophys Res 101:4595-4622.

Meadows, V.S. and Seager, S. (2010) Terrestrial planet atmospheres and biosignatures. In Exoplanets, edited by S. Seager, University of Arizona Press, Tucson, AZ, pp 441470.

Meadows, V.S., Arney, G.N., Schwieterman, E.W., LustigYaeger, J., Lincowski, A.P., Robinson, T., DomagalGoldman, S.D., Barnes, R.K., Fleming, D.P., Deitrick, R., Luger, R., Driscoll, P.E., Quinn, T.R., and Crisp, D. (2016) The habitability of Proxima Centauri b: II: environmental states and observational discriminants. arXiv: 1608.08620

Mennesson, B., Gaudi, S., Seager, S., Cahoy, K., DomagalGoldman, S., Feinberg, L., Guyon, O., Kasdin, J., Marois, C., Mawet, D., Tamura, M., Mouillet, D., Prusti, T., Quirrenbach, A., Robinson, T., Rogers, L., Scowen, P., Somerville, R., Stapelfeldt, K., Stern, D., Still, M., Turnbull, M., Booth, J., Kiessling, A., Kuan, G., and Warfield, K. (2016) The Habitable Exoplanet (HabEx) Imaging Mission: preliminary science drivers and technical requirements. Proc SPIE 9904, doi: $10.1117 / 12.2240457$.

Olson, S.L., Kump, L.R., and Kasting, J.F. (2013) Quantifying the areal extent and dissolved oxygen concentrations of Archean oxygen oases. Chem Geol 362:35-43.

Olson, S.L., Reinhard, C.T., and Lyons, T.W. (2016) Limited role for methane in the mid-Proterozoic greenhouse. Proc Natl Acad Sci USA 113:11447-11452.

Ono, S., Eigenbrode, J.L., Pavlov, A.A., Kharecha, P., Rumble, D., III, Kasting, J.F., and Freeman, K.H. (2003) New insights into Archean sulfur cycle from mass-independent sulfur isotope records from the Hamersley Basin, Australia. Earth Planet Sci Lett 213:15-30.

Partin, C.A., Bekker A., Planavsky, N.J., Scott, C.T., Gill, B.C., Li, C., Podkovyrov, V., Maslov, A., Konhauser, K.O., Lalonde, S.V., Love, G.D., Poulton, S.W., and Lyons, T.W. (2013) Large-scale fluctuations in Precambrian atmospheric and oceanic oxygen levels from the record of $U$ in shales. Earth Planet Sci Lett 369-370:284-293.

Pavlov, A.A. and Kasting, J.F. (2002) Mass-independent fractionation of sulfur isotopes in Archean sediments: strong evidence for an anoxic Archean atmosphere. Astrobiology 2:27-41.

Pavlov, A.A., Kasting, J.F., and Brown, L.L. (2000) Greenhouse warming by $\mathrm{CH}_{4}$ in the atmosphere of early Earth. $J$ Geophys Res 105:11981-11990.

Pavlov, A.A., Hurtgen, M.T., Kasting, J.F., and Arthur, M.A. (2003) Methane-rich Proterozoic atmosphere? Geology 31: 87-90.

Pierrehumbert, R.T. (2013) Strange news from other stars. Nat Geosci 6:81-83.

Pilcher, C.B. (2003) Biosignatures of early Earths. Astrobiology 3:471-486.

Planavsky, N.J., McGoldrick, P., Scott, C.T., Li, C., Reinhard, C.T., Kelly, A.E., Chu, X.L., Bekker, A., Love, G.D., and 
Lyons, T.W. (2011) Widespread iron-rich conditions in the mid-Proterozoic ocean. Nature 477:448-451.

Planavsky, N.J., Bekker, A., Hofmann, A., Owens, J.D., and Lyons, T.W. (2012) Sulfur record of rising and falling marine oxygen and sulfate levels during the Lomagundi event. Proc Natl Acad Sci USA 109:18300-18305.

Planavsky, N.J., Asael, D., Hofmann, A., Reinhard, C.T., Lalonde, S.V., Knudsen, A., Wang, X., Ossa Ossa, F., Pecoits, E., Smith, A.J.B., Beukes, N.J., Bekker, A., Johnson, T.M., Konhauser, K.O., Lyons, T.W., and Rouxel, O.J. (2014a) Evidence for oxygenic photosynthesis half a billion years before the Great Oxidation Event. Nat Geosci 7:283-286.

Planavsky, N.J., Reinhard, C.T., Wang, X., Thomson, D., McGoldrick, P., Rainbird, R.H., Johnson, T.M., Fischer, W.W., and Lyons, T.W. (2014b) Low mid-Proterozoic atmospheric oxygen levels and the delayed rise of animals. Science 346:635-638.

Poulton, S.W. and Canfield D.E. (2011) Ferruginous conditions: a dominant feature of the ocean through Earth's history. Elements 7:107-112.

Reeburgh, W.S. (2007) Oceanic methane biogeochemistry. Chem Rev 107:486-513.

Regnier, P., Dale, A.W., Arndt, S., LaRowe, D.E., Mogollón, J., and Van Cappellen, P. (2011) Quantitative analysis of anaerobic oxidation of methane (AOM) in marine sediments: a modeling perspective. Earth-Science Reviews 106:105-130.

Reinhard, C.T., Raiswell, R., Scott, C., Anbar, A.D., and Lyons, T.W. (2009) A Late Archean sulfidic sea stimulated by early oxidative weathering of the continents. Science 326:713-716.

Reinhard, C.T., Lalonde, S., and Lyons, T.W. (2013a) Oxidative sulfide dissolution on the early Earth. Chem Geol 362: 44-55.

Reinhard, C.T., Planavsky, N.J., and Lyons, T.W. (2013b) Long-term sedimentary recycling of rare sulphur isotope anomalies. Nature 297:100-103.

Reinhard, C.T., Planavsky, N.J., Robbins, L.J., Partin, C.A., Gill, B.C., Lalonde, S.V., Bekker, A., Konhauser, K.O., and Lyons, T.W. (2013c) Proterozoic ocean redox and biogeochemical stasis. Proc Natl Acad Sci USA 110:5357-5362.

Reinhard, C.T., Planavsky, N.J., Olson, S.L., Lyons, T.W., and Erwin, D.H. (2016) Earth's oxygen cycle and the evolution of animal life. Proc Natl Acad Sci USA 113:8933-8938.

Riedinger, N., Formolo, M.J., Lyons, T.W., Henkel, S., Beck, A., and Kasten, S. (2014) An inorganic geochemical argument for coupled anaerobic oxidation of methane and iron reduction in marine sediments. Geobiology 12:172-181.

Robinson, T.D., Meadows, V.S., and Crisp, D. (2010) Detecting oceans on extrasolar planets using the glint effect. Astrophys J 721:L67-L71.

Robinson, T.D., Meadows, V.S., Crisp, D., Deming, D., A'Hearn, M.F., Charbonneau, D., Livengood, T.A., Seager, S., Barry, R.K., Hearty, T., Hewagama, T., Lisse, C.M., McFadden, L., and Wellnitz, D.D. (2011) Earth as an extrasolar planet: Earth model validation using EPOXI Earth observations. Astrobiology 11:393-408.

Robinson, T.D., Ennico, K., Meadows, V.S., Sparks, W., Bussey, D.B.J., Schwieterman, E.W., and Breiner, J. (2014) Detection of ocean glint and ozone absorption using LCROSS Earth observations. Astrophys J 787, doi:10.1088/0004-637X/ 787/2/171.

Robinson, T.D., Stapelfeldt, K.R., and Marley, M.S. (2016) Characterizing rocky and gaseous exoplanets with $2 \mathrm{~m}$ class space-based coronagraphs. Publ Astron Soc Pac 128, doi:10.1088/1538-3873/128/960/025003.
Rye, R. and Holland, H.D. (1998) Paleosols and the evolution of atmospheric oxygen: a critical review. Am J Sci 298:621672.

Sagan, C., Thompson, W.R., Carlson, R., Gurnett, D., and Hord, C. (1993) A search for life on Earth from the Galileo spacecraft. Nature 365:715-721.

Sahoo, S.K., Planavsky, N.J., Jiang, G., Kendall, B., Owens, J.D., Wang, X., Shi, X., Anbar, A.D., and Lyons, T.W. (2016) Oceanic oxygenation events in the anoxic Ediacaran ocean. Geobiology 14:457-468.

Schröder, S., Bekker, A., Beukes, N.J., Strauss, H., and van Niekerk, H.S. (2008) Rise in seawater sulphate concentration associated with the Paleoproterozoic positive carbon isotope excursion: evidence from sulphate evaporites in the $\sim 2.2-$ 2.1 Gyr shallow-marine Lucknow Formation, South Africa. Terra Nova 20:108-117.

Schwieterman, E.W., Robinson, T.D., Meadows, V.S., Misra, A., and Domagal-Goldman, S. (2015) Detecting and constraining $\mathrm{N}_{2}$ abundances in planetary atmospheres using collisional pairs. Astrophys J 810, doi:10.1088/0004-637X/ $810 / 1 / 57$.

Schwieterman, E.W., Meadows, V.S., Domagal-Goldman, S.D., Deming, D., Arney, G.N., Luger, R., Harman, C.E., Misra, A., and Barnes, R. (2016) Identifying planetary biosignature impostors: spectral features of $\mathrm{CO}$ and $\mathrm{O}_{4}$ resulting from abiotic $\mathrm{O}_{2} / \mathrm{O}_{3}$ production. Astrophys $J$ 819:L13.

Seager, S. (2013) Exoplanet habitability. Science 340:577-581. Seager, S. (2014) The future of spectroscopic life detection on exoplanets. Proc Natl Acad Sci USA 111:12634-12640.

Seager, S. and Deming, D. (2011) Exoplanet atmospheres. Annu Rev Astron Astrophys 48:631-672.

Seager, S., Bains, W., and Hu, R. (2013a) A biomass-based model to estimate the plausibility of exoplanet biosignature gases. Astrophys J 775, doi:10.1088/0004-637X/775/2/104.

Seager, S., Bains W., and Hu, R. (2013b) Biosignature gases in $\mathrm{H}_{2}$-dominated atmospheres on rocky exoplanets. Astrophys $J$ 777, doi:10.1088/0004-637X/777/2/95.

Segura, A., Meadows, V.S., Kasting, J.F., Crisp, D., and Cohen, M. (2007) Abiotic formation of $\mathrm{O}_{2}$ and $\mathrm{O}_{3}$ in high- $\mathrm{CO}_{2}$ terrestrial atmospheres. Astron Astrophys 472:665-679.

Sivan, O., Adler, M., Pearson, A., Gelman, F., Bar-Or, I., John, S.G., and Eckert, W. (2011) Geochemical evidence for ironmediated anaerobic oxidation of methane. Limnol Oceanogr 56:1536-1544.

Snellen, I.A.G., de Kok, R.J., le Poole, R., Brogi, M., and Birkby, J. (2013) Finding extraterrestrial life using groundbased high-dispersion spectroscopy. Astrophys $J$ 764, doi: 10.1088/0004-637X/764/2/182.

Snellen, I.A.G., de Kok, R.J., Birkby, J.L., Brandl, B., Brogi, M., Keller, C.U., Kenworthy, M., Schwarz, H., and Stuik, R. (2015) Combining high-dispersion spectroscopy with high contrast imaging: probing rocky planets around our nearest neighbors. Astron Astrophys 576:A59.

Sperling, E.A., Rooney, A.D., Hays, L.E., Sergeev, V.N., Vorob'eva, N.G., Sergeeva, N.D., Selby, D., Johnston, D.T., and Knoll, A.H. (2014) Redox heterogeneity of subsurface waters in the Mesoproterozoic ocean. Geobiology 12:373386.

Tang, D., Shi, X., Wang, X., and Jiang, G. (2016) Extremely low oxygen concentration in mid-Proterozoic shallow seawaters. Precambrian Res 276:145-157.

Thomson, D., Rainbird, R.H., Planavsky, N., Lyons, T.W., and Bekker, A. (2015) Chemostratigraphy of the Shaler Supergroup, Victoria Island, NS Canada: a record of ocean com- 
position prior to the Cryogenian glaciations. Precambrian Res 263:232-245.

Tinetti, G., Meadows, V.S., Crisp, D., Fong, W., Velusamy, T., and Snively, H. (2005) Disk-averaged synthetic spectra of Mars. Astrobiology 5:461-482.

Ueno, Y., Johnson, M.S., Danielache, S.O., Eskebjerg, C., Pandey, A., and Yoshida, N. (2009) Geological sulfur isotopes indicate elevated OCS in the Archean atmosphere, solving faint young Sun paradox. Proc Natl Acad Sci USA 106:14784-14789.

Valentine, D.L. (2011) Emerging topics in marine methane biogeochemistry. Ann Rev Mar Sci 3:147-171.

Wordsworth, R. and Pierrehumbert R.T. (2014) Abiotic oxygen-dominated atmospheres on terrestrial habitable zone planets. Astrophys J 785:L20.

Zahnle, K.J., Claire, M., and Catling, D. (2006) The loss of massindependent fractionation in sulfur due to a Paleoproterozoic collapse of atmospheric methane. Geobiology 4:271-283.
Address correspondence to: Christopher T. Reinhard School of Earth and Atmospheric Sciences Georgia Institute of Technology 311 Ferst Dr. Atlanta, GA 30332

E-mail: chris.reinhard@eas.gatech.edu

Submitted 28 September 2016 Accepted 23 January 2017

\section{Abbreviations Used \\ $\mathrm{GOE}=$ Great Oxidation Event \\ $\mathrm{PAL}=$ present atmospheric level}

